\title{
Kinetic subjective contours
}

\author{
PHILIP J. KELLMAN and MARGARET H. COHEN \\ Swarthmore College, Swarthmore, Pennsylvania
}

\begin{abstract}
Continuous changes in spatially separated figures can evoke perception of subjective contours and figures in physically homogeneous space between them. This occurs when all of the interruptions in the objectively present patterns (inducing elements) can be seen as caused by a unitary figure partly occluding them. Two experiments demonstrated and explored this phenomenon. In both, displays were presented to subjects under three conditions. In one condition, stationary inducing elements were shown as they would be interrupted by a figure rotating in front of them. In another condition, the background and inducing elements rotated, with interruptions occurring as if a stationary figure were in front. In a third condition, observers were shown 10 static views taken from the figure-rotation sequence for each display. Subjects consistently perceived unitary central figures with well-defined forms and clear edges from pattern changes given by figure movement and background movement. As with static subjective figures, kinetic subjective figures appear in front of, partly occluding, the inducing elements. These percepts form rapidly, and they depend upon temporal relations rather than upon information present in momentary views. Subjects occasionally reported subjective edges or a central figure in the stationary displays in Experiment 1, but not at all in Experiment 2, in which guessing tendencies were reduced by more specific instructions. The existence of kinetic subjective contours suggests that the visual system readily utilizes relationships among occlusion events separated in space and time. The minimum conditions for contour perception require neither information all along an edge nor simultaneous specification of the edge at two or more places.
\end{abstract}

This paper reports the existence of kinetic subjective contours. Ordinary subjective contours are edges perceived in stationary displays in the absence of luminance differences (Kanizsa, 1955, 1979; Schumann, 1904). These are produced by certain spatial arrangements of figures with gaps in them (see Figure 1), so that a single interposed figure might be responsible for all of the gaps. The figures with gaps, or "inducing elements," are then seen as regular, partly occluded figures, and a subjective figure is seen in front of them.

Subjective contours have been the subject of continuing theoretical dispute. A major issue has been whether the primary causal factor in perceiving subjective contours is brightness contrast (Brigner \& Gallagher, 1974; Frisby \& Clatworthy, 1975) or some higher order factor, such as a tendency toward simplicity (Kanizsa, 1979) or implicit interposition cues given by figural irregularities (Coren, 1972).

A strong case can be made that organizational factors, rather than brightness contrast, underlie the sub-

A version of this paper was presented at the Second International Conference on Event Perception, Vanderbilt University, Nashville, Tennessee, in June 1983. This work was supported by a Faculty Grant from Swarthmore College to P.J.K. The authors thank Robert Becklen and Barry Schwartz for helpful comments, and Ken Short for help in preparing the manuscript. M. H. Cohen is now at Harvard Law School. Reprint requests should be sent to Philip J. Kellman, Department of Psychology, Swarthmore College, Swarthmore, PA 19081.

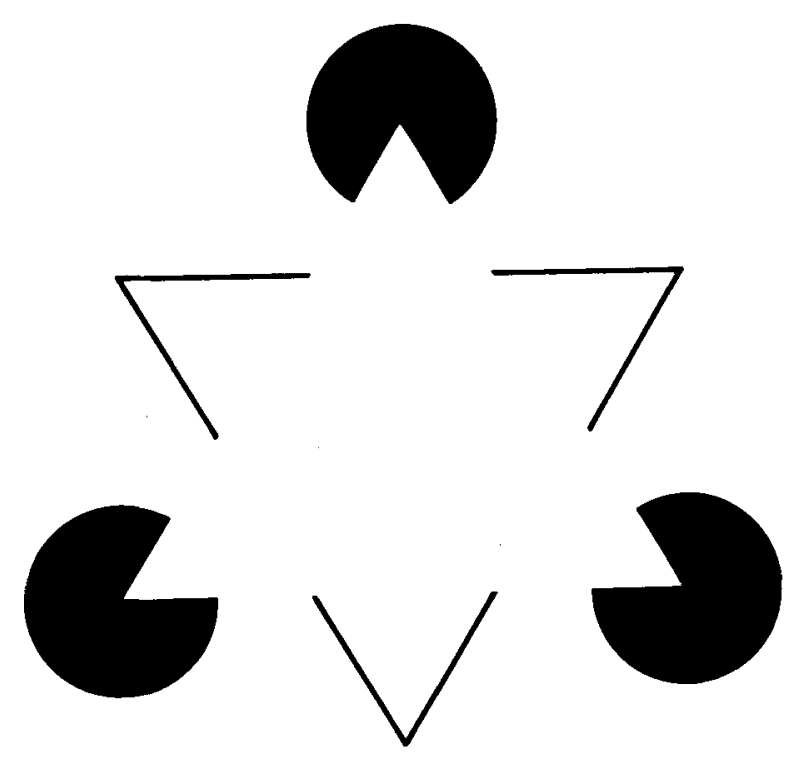

Figure 1. An ordinary subjective contour display (from Kanizan, 1979).

jective contour phenomenon (Coren, 1972; Dumais \& Bradley, 1976; Kellman \& Cohen, 1983; Rock \& Anson, 1979). Figural irregularities in certain arrangements lead to perception of connected edges and unitary figures responsible for the irregularities. Since the visual system utilizes figural irregularities suitably arranged in space as indicators of an inter- 

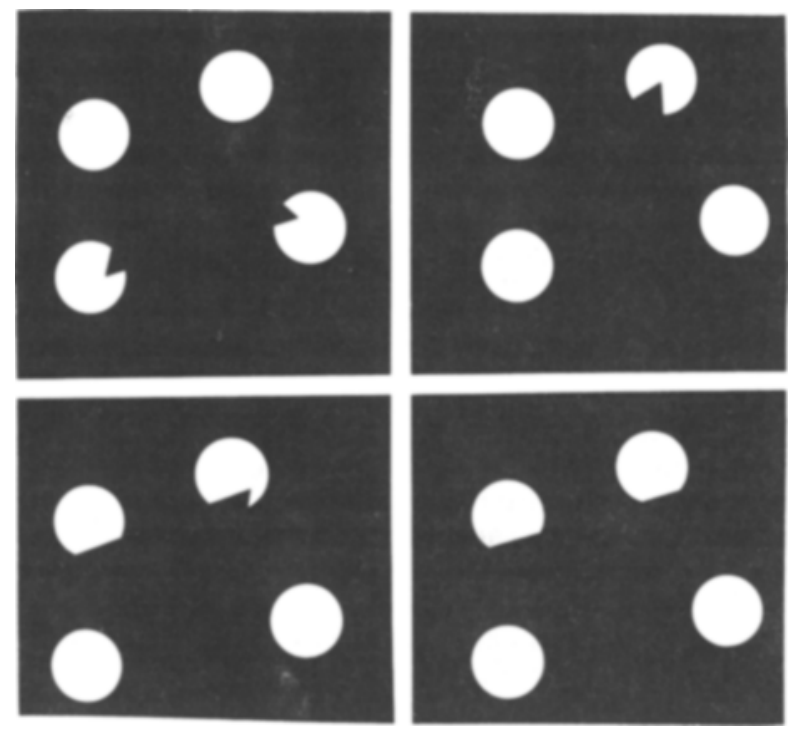

Figure 2. Example of a kinetic subjective contour display. The interruptions in the circles shown in the four views would occur at different times during the continuous movement of the (otherwise invisible) central figure.

posed figure, we hypothesized that figural irregularities appropriately related over time might also produce subjective contours. An example is schematized in Figure 2. Interruptions in the white circles appear over time as they would if there were a black triangle rotating in front of them. Although, in the actual displays, these changes occur continuously, Figure 2 shows several static views taken from the rotation sequence. The displays were constructed so that no static view would lead to perception of a subjective figure.

\section{EXPERIMENT 1}

To test for the existence of kinetic subjective contours, we presented displays of the sort described above in kinetic and static conditions. If subjects perceive subjective edges and figures in these moving displays, but not in static views, such contours must be based on spatial and temporal relations of the occlusion patterns.

\section{Method}

Subjects. The subjects were eight Swarthmore College undergraduates who had not studied perception. Each was paid $\mathbf{\$ 1}$ for participating.

Dhplays and Apparatus. Each display consisted of white inducing elements on a black background, presented on a videotape monitor. In each case, the white figures were interrupted over time as they would be if an opaque figure of the same color as the background moved in front of them. Displays were constructed by videotaping actual black figures in front of the background and adjusting the video monitor so that no real edges (i.e., specified by luminance differences) were visible. The four display types are shown along the abscissa of Figure 3 and also Figure 4. They con- sisted of: (1) an isosceles triangle (nearly equilateral) interrupting four circles, (2) a scalene triangle (nearly a right triangle) interrupting two rectangles, (3) a triangular figure with one corner clipped, interrupting two rectangles-this figure was also the outline of one view of a triangular solid-and (4) a hexagon interrupting two rectangles. The displays were constructed from black cardboard and white adhesive labels. The black figure was always positioned $1 \mathrm{~cm}$ in front of the background, and a motor could be connected to turn either the figure or the background. Moving parts of the displays made one complete revolution every $2.5 \mathrm{sec}$. The displays were viewed from a distance of $2.8 \mathrm{~m}$. The visual angle subtended by the inducing elements and the central area together was about $2.2 \mathrm{deg}$ (horizontal) and $2.6 \mathrm{deg}$ (vertical) for all displays. In the static condition, each view was shown for $5 \mathrm{sec}$ and a large black card occluded the camera for $1 \mathrm{sec}$ while the static position was changed. The static views for each display were chosen to be about equally spaced around the rotation cycle, subject to the constraint that they be maximally informative. That is, positions were chosen in which figural interruptions were as extensive as possible. Illumination was provided by a single $93-\mathrm{W}$ bulb, $2 \mathrm{~m}$ away and aimed directly at the displays to minimize shadows. There was no position in any display in which every corner of the interposed figure overlay the white figures.

Design. The subjects were shown the four displays in three different conditions: (1) a series of 10 static views with the interruptions in the inducing elements in different positions, (2) displays in which figural interruptions occurred from continuous rotation of a figure in front of the inducing elements, and (3) displays in which the background containing the inducing elements rotated, with interruptions caused by a stationary figure in front. The four sets of static views were shown first to all subjects, with presentation order counterbalanced across subjects according to a Latin square. The eight moving displays were shown afterward, also in orders determined by a Latin square.

Procedure. The subjects were tested in a dark room; they were seated $2.8 \mathrm{~m}$ from the monitor. They were shown each display and asked, "What do you see?" and "How many objects are in the display?" The subjects were scored as perceiving a unitary central figure if they reported the total number of objects to be one more than the number of inducing elements and described the extra object as centrally located with a color similar to that of the background. If they did report a central black figure, they were asked: (1) "Does it have a definite shape?" (2) "Is it symmetrical, or are any of the sides of the same length?" and (3) "Is it a flat pattern or three-dimensional?" The subjects were scored for correct shape reports according to strict criteria: both a correct verbal label for the shape and the correct answer concerning sides of the same length were required. For example, the subjects were not scored as accurately perceiving shape if they reported as a right triangle the slightly scalene triangle, or if they reported as equilateral the isosceles triangle. If the subjects saw a series of notches in the white inducing elements rather than a central figure, they were asked whether the white elements had definite shape. The experiment took about $20 \mathrm{~min}$.

Dependent measures and data analysis. We recorded for each subject and each display (with each series of static views counted as one display): (1) whether the interruptions in the inducing elements were seen to be caused by a unitary entity (2) whether the shape of the occluding figure was accurately reported, and (3) whether the occluding figure appeared flat or three-dimensional. Each question served a separate purpose. The unity question assessed the possibility that subjects could perceive certain figural irregularities as releated without seeing clear edges or shape. The report of a specific, bounded shape was the most direct test of the existence of kinetic subjective contours. Finally, pilot work indicated a tendency for the hexagonal display to appear as a subjective three-dimensional cube for some observers. The question about three-dimensionality was added to explore this aspect of the kinetic subjective contour phenomenon. The irregular triangular pattern, which could be seen as a view of a pyramid, was also added for this reason. 


\section{Results}

Kinetic subjective contours and figures were perceived by all subjects under both movement conditions. Figures 3 and 4 show, respectively, the number of subjects reporting that figural interruptions were caused by a unitary entity and the number of subjects reporting accurate shape, by display and viewing condition. When the background moved, all subjects perceived unitary subjective figures and accurate shape for all four displays. When the changes in the display were produced by a moving figure, all subjects reported unitary entities with all of the displays, and most reported specific form accurately. Moreover, the inducing figures were perceived to be of constant shape, with their changing visible areas being due to partial occlusion. Unity and form were not often perceived from the stationary sequences. Subjects typically reported white figures with "nicks" or "chunks taken out." Binomial tests ${ }^{1}$ (Siegel, 1956, pp. 66-67) were used to determine whether subjects reported unity and form reliably more often in one viewing condition than in another. In eliciting accurate shape reports, the background-movement condition was reliably superior to the static condition for each of the four displays ( $p<.05$ in the worst case). The figure-movement condition was reliably superior to the static condition for all displays except the isosceles triangle against the circles, for which the difference was only marginally significant $(.05<\mathrm{p}<.10)$. This display was misidentified by three subjects in the figure-movement condition: two said that it had three sides of different lengths and one reported a four-pointed rotating object. There were no significant differences between the number of subjects reporting correct shape for the two movement conditions with any display (all ps $>.13$ ). All subjects re-

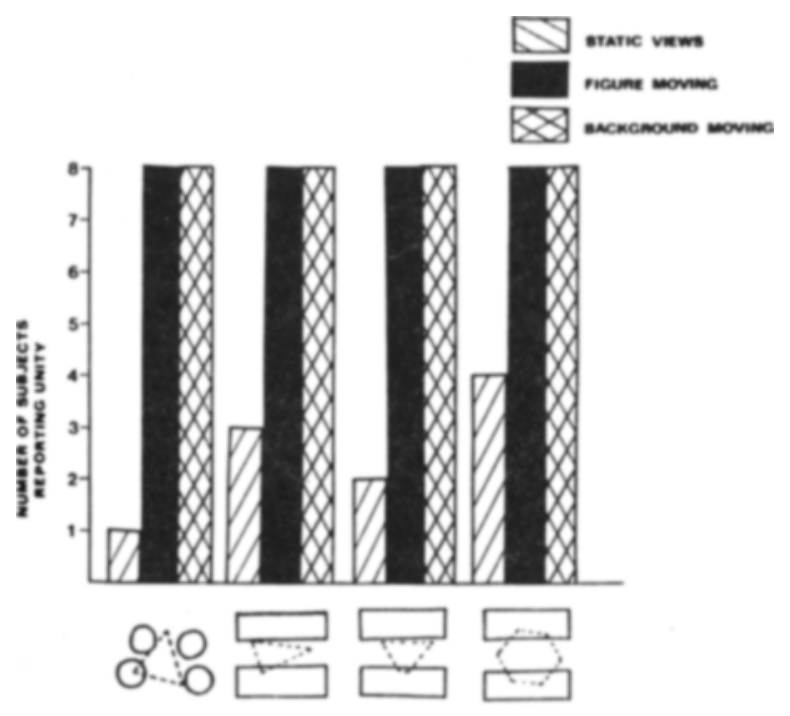

Figare 3. Number of subjects reporting a unitary central figure, by viewing condition and display in Experiment 1.

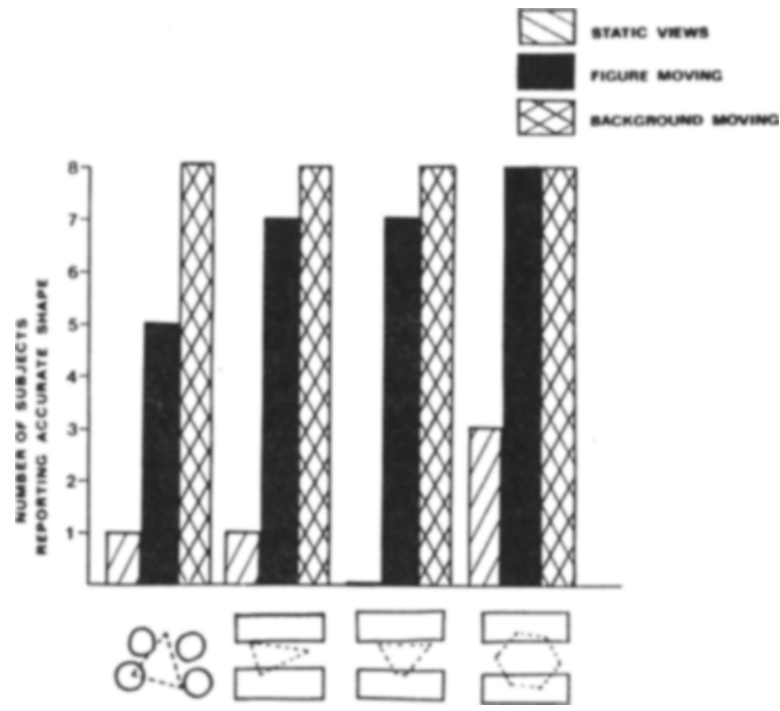

Figure 4. Number of subjects accurately reporting shape of subjective figure, by viewing condition and display in Experiment 1.

ported unity with all displays under both movement conditions. Each movement condition elicited reliably more reports of unity than did the static condition for all displays except the hexagon, for which the difference was marginally significant $(.05<\mathrm{p}<$ $.10)$. This was due to the fact that four subjects reported unity from the static sequence for that display. No more than one subject reported a three-dimensional central figure for any display except the hexagon. Five of the eight subjects saw this display as threedimensional in the figure-movement condition; in the background-movement and static conditions, only one subject reported three-dimensionality.

\section{Discussion}

Well-defined subjective figures were perceived from kinetic occlusion patterns separated in space and time. These percepts did not rely on information available in static views of the displays. Perception of unity and of well-defined shape were both reliably better in the motion conditions than in the static condition. Kinetic subjective figures seemed to be most easily perceived when the occlusion patterns were consistent with an interposed figure in a fixed position, that is, when the background moved. Results for three of the displays were numerically better in the background-movement than in the figure-movement condition. While not statistically significant, a real difference may exist between these conditions, obscured by the fact that figural perception in the background-movement condition was at ceiling for all displays. The reports of three-dimensionality by a majority of subjects viewing the hexagon in the figure-movement condition is intriguing. The same display was seen as three-dimensional by only one subject when the background moved. Another dis- 
play which could have been seen as a solid pyramid, and was quite irregular as a two-dimensional pattern, was seen as three-dimensional by only one subject when the figure moved and was always seen as twodimensional in the other conditions. Whether there are stimulus conditions that reliably evoke perception of three-dimensionality in this context, and what those might be, cannot be decided from the present data.

Although Experiment 1 suggests the existence of a new phenomenon-kinetic subjective contourssubjects in this experiment did occasionally report a unitary central figure and specific shape from the static displays. Such reports raise the question of whether kinetic subjective contours are qualitatively different from the well-known static variety. It was possible, for example, that the relevant information leading to figural perception in the kinetic cases was also present in the static views, but that there were simply more views in the former. ${ }^{2}$ Our impressions from subjects' responses pointed in quite the opposite direction. We noticed that the few reports of unity and form in the static cases seemed hesitant and based on guessing or inference, whereas reports in the movement conditions were unequivocal and rapid. However, speed of response was not measured in the first experiment, and the generality of our initial question to subjects ("What do you see?") may have encouraged guessing about how the figural irregularities in the static views could be related. Another shortcoming of Experiment 1 was that we did not specifically ask subjects about the depth relations of the central figure and the surrounding figures, although many subjects spontaneously reported that the subjective figure was in front of, and partly occluding, the inducing elements. If kinetic subjective contours are based on kinetic optical occlusion and are analogous to static subjective contours, we would expect the subjective figures to appear in front of and partly occluding the inducing elements.

\section{EXPERIMENT 2}

Our second experiment was therefore designed to minimize guessing tendencies, by using more specific instructions, and to obtain latency data and depth judgments. Rather than asking, "What do you see," we asked subjects to press a button upon perception of a well-defined central figure. The experiment also included two practice displays used to check on the subjects' interpretations of the instructions. If our static and kinetic conditions were providing similar information in different quantities, these instructions should not change the relative tendencies to report figures in the kinetic and static conditions. If, however, the few reports of unity and form in the previous static conditions were based on conscious "ffig- uring out" of the displays, we would expect such reports to be reduced or eliminated by the new instructions.

\section{Method}

Subjects. The subjects were 10 Swarthmore College undergraduates who had not studied perception. Each was paid \$2 for participating. None had served as a subject in Experiment 1.

Displays and Apparatus. The displays were presented in the same format as in Experiment 1. Two displays were used, each in three conditions: figure movement, background movement, and static views. One display was the third figure used in Experiment 1-a triangular figure with one corner clipped, interrupting two rectangles. The other figure was an equilateral triangle very similar to the isosceles triangle in Experiment 1, except that it was actually equilateral. This figure was specified by interruptions in four circles, spaced as with the isosceles triangle. Two practice displays were used to check the subjects' understanding of instructions. One was a stationary subjective contour display-a version of the Kanisza triangle. It consisted of a black background on which were placed three white circles, of radius $1.9 \mathrm{~cm}$, with $60-$ deg notches cut out and arranged to partly define an equilateral triangle with sides of $5 \mathrm{~cm}$. At the observers' viewing distance, a side of the triangle subtended about $1 \mathrm{deg}$ of visual angle. The other practice display was designed to evoke no perception of a subjective figure; it served as a check on whether subjects were guessing or inferring a possible central figure. The display consisted of three angle-shaped elements placed at the corners of an imaginary equilateral triangle, $7.5 \mathrm{~cm}$ per side and about $1.6 \mathrm{deg}$ of visual angle. Each element had two white arms, $1.9 \mathrm{~cm}$ long and $.35 \mathrm{~cm}$ thick, meeting in a 60-deg angle. Such a display has been reported previously not to give rise to subjective contours (Coren, 1972).

Design. The subjects were first shown the two practice displays. The six experimental displays (two figures, three conditions) were shown in a different random order to each subject.

Procedure. The subjects were read the following instructions: "I am going to show you several displays on videotape. Some of them will remain the same as you view them, while others will have changes occurring. In each case there will be two or more white figures on the screen. Your task is to watch each display and press the button if you see another figure of a color similar to the background (which will always be black) in the central area between the white figures. Press only if you see a well-defined figure with definite edges and shape. If you do see a central figure, press the button as soon as possible. You may see such a central figure immediately, sometime during the viewing period, or not at all. It is perfectly all right not to press the button on a given trial. In such a case, the trial will last for $\mathbf{6 0}$ seconds and I will signal its end. For trials on which you do press the button, I will ask you a few questions about what you saw. To familiarize you with the task, I will give you some feedback on the first two displays. Do you understand the instructions?"

If a subject indicated he or she did not understand, the relevant parts of the instructions were read again. On all displays, if a subject pressed the button, he or she was then asked the following four questions: (1) What is the shape of the central figure? (2) Are any of its sides the same length? (3) Is it a flat pattern or threedimensional? (4) What are the depth relations between the central figure and the white figures: Is the central figure in the same plane, nearer, or further away? If a subject reported that the central figure was nearer, he or she was asked: $(4 a)$ Does the central figure overlap the others?

The practice display, consisting of a static subjective contour, was shown first. If a subject did not press the button to signal perception of a clear central figure within $30 \mathrm{sec}$, the experimenter asked whether the subject saw such a figure and told him or her to press the button if he or she did. Only one subject required prompting in this manner; he did notice a central figure with clear edges, but had some uncertainty about the instructions. Another subject hesitated for $21.9 \mathrm{sec}$ before pressing the button. The 
remaining eight subjects averaged $4.4 \mathrm{sec}$ to press the button. After the buttonpress, the experimenter gave feedback to the subject by saying, "That's good. Press the button when you see a central figure with clear edges." Next, the angle display was shown. Most subjects (seven) did not press the button during the 60-sec trial. At the end of the trial, the experimenter said, "That's good. If you do not see a well-defined central figure, do not press the button." Three subjects did press the button at some time during the trial. In all cases they were asked, "Do you see a definite figure with clear edges in the central area?" In all cases they answered "No," but explained that they could infer or imagine such a figure from parts of the display. These subjects were then told that they should only report central figures that were plainly visible, and that they should not infer or guess. The practice displays served to sharpen subjects' understanding of the instructions. Since both displays on which feedback was given were stationary, this procedure should not have biased subjects toward figure reporting in later moving displays or against it in later static displays.

After the practice displays, the six experimental displays were shown. The interval between displays was about $60 \mathrm{sec}$, during which the monitor was covered by a sheet of black cardboard.

Dependent mensures. Whether or not a central figure was reported and the latency of buttonpresses were recorded for each display. Shape reports were scored as accurate if the subject gave an acceptable verbal description (see below) and correctly reported the number of sides that were the same length (all three in the case of the equilateral triangle; two in the case of the other figure). Acceptable verbal descriptions were "triangle" or "equilateral triangle" for one display and "triangular figure with a corner clipped off" or "irregular quadrilateral" for the other.

\section{Results and Discussion}

Table 1 shows the major results of this study. All subjects signaled the presence of well-defined subjective figures in the kinetic conditions, and none indicated subjective figures in the static presentations. This result suggests that the few reports of unity and form in the static conditions of Experiment 1 were due to guessing or inference by subjects rather than actual perception of a clear subjective figure. The more specific instructions and/or the practice displays used in this study eliminated reports of a central figure in the static cases but did not diminish subjects' reports of kinetic subjective figures. The guessing hypothesis is further confirmed by subjects' responses to the practice displays. Three subjects pressed the button at some time during the exposure of the angle display, which does not produce subjective contours. Especially given the emphatic instructions used in this experiment, these cases indicate that guessing tendencies are quite strong for some subjects. It seems likely that these tendencies were responsible for the occasional unity and form reports in the static conditions of Experiment 1. Taken together, Experiments 1 and 2 suggest that subjective figures and edges perceived from kinetic optical occlusion events are qualitatively different from percepts attainable from static views.

As in Experiment 1, kinetic information consistently provided accurate information about the shape of the central figure, as well as its unity. In this study, subjects were also explicitly questioned about the depth relations between the subjective figure and the inducing elements. Nine of the 10 subjects reported that the subjective figure was nearer than, and overlying (at times), the surrounding white patterns. ${ }^{3}$ This result indicates that kinetic subjective contours yield depth effects similar to those found with static subjective contours.

The latency data indicate that kinetic subjective contours appear rapidly. From the median response time, it is obvious that many reports were based on less than one complete rotation of figure or background. In fact, many observed latencies approach the minimum time required with these displays for all corners of a figure to interrupt some background element (about $1 \mathrm{sec}$ ). With a latency of $1.5 \mathrm{sec}$, which was not uncommon, each corner may be occluding some background element for as little as $.5 \mathrm{sec}$. Also of interest is the fact that the mean latencies for all of the kinetic displays were similar to or slightly less than the mean latency for the static practice display (for the eight subjects who had no problem with the instructions). The reliable and rapid onset of perceived edges and figures seems inconsistent with any explicit guessing by subjects. It is consistent with other reports of the rapidity of the pickup of motion relationships (e.g., Johansson, 1975).

\section{GENERAL DISCUSSION}

The discovery of kinetic subjective contours coheres with and extends our understanding of several

Table 1

Subjective Figure Reporting, Latency (in Seconds), Shape and Depth Data in Experiment 2

\begin{tabular}{|c|c|c|c|c|}
\hline Display & $\begin{array}{c}\text { Number } \\
\text { Reporting } \\
\text { Subjective Figure* }\end{array}$ & Latency** & $\begin{array}{c}\text { Number } \\
\text { Reporting } \\
\text { Correct Shape* }\end{array}$ & $\begin{array}{l}\text { Number } \\
\text { Reporting } \\
\text { Overlap* }\end{array}$ \\
\hline \multicolumn{5}{|c|}{ Equilateral Triangle } \\
\hline $\begin{array}{l}\text { Static Views } \\
\text { Figure Movement } \\
\text { Background Movement }\end{array}$ & $\begin{array}{r}0 \\
10 \\
10\end{array}$ & $\begin{array}{l}>60 \\
3.3(2.8) \\
3.8(2.3)\end{array}$ & $\begin{array}{l}10 \\
10\end{array}$ & $\begin{array}{l}9 \\
9\end{array}$ \\
\hline \multicolumn{5}{|c|}{ Irregular Quadrilateral } \\
\hline $\begin{array}{l}\text { Static Views } \\
\text { Figure Movement } \\
\text { Background Movement }\end{array}$ & $\begin{array}{r}0 \\
10 \\
10\end{array}$ & $\begin{array}{l}>60 \\
3.9(3.8) \\
3.3(2.9) \\
\end{array}$ & $\begin{array}{r}9 \\
10\end{array}$ & $\begin{array}{l}9 \\
9 \\
\end{array}$ \\
\hline
\end{tabular}

${ }^{*} n=10 . \quad$ **Medians shown in parentheses. 
related perceptual phenomena. Kinetic specification of occluding edges has been investigated extensively (Gibson, 1979; Gibson, Kaplan, Reynolds, \& Wheeler, 1969; Kaplan, 1969; Michotte, Thinés, \& Crabbé, 1964). The inducing areas in our displays are examples of Michotte's "kinetic optical occlusion" effects (Michotte et al., 1964). Changes in the shapes of figures, rather than accretion and deletion of texture elements (Kaplan, 1969), specifies the occluding edge. (It is possible, of course, that accretion-deletion and kinetic optical occlusion may depend on the same visual mechanisms.) The present effects extend previous work on occluding edges in that the contours perceived are not specified along their entire length. Kinetic subjective contours indicate that spatially and temporally separated occurrences of kinetic optical occlusion may specify well-defined edges across homogeneous space.

Kinetic subjective contours are closely related to ordinary subjective contours. Both depend on spatial relations and figural interruption, and the figures perceived partly occlude the inducing elements. Kinetic subjective contours depend, in addition, on temporal relationships. However, stationary subjective contours may require explanation in terms of simplicity or probability (Kanizsa, 1979), but kinetic subjective contours may not. When patterns cannot be seen as incomplete, irregular, or improbable, static subjective contours do not occur (Coren, 1972; Kanizsa, 1979; Rock \& Anson, 1979). The ability of continuously transforming patterns to specify an occluding edge does not require any implicit assumption that objects have simple shapes, but it may depend on a rigidity principle (cf. Ullman, 1979). In Michotte's demonstrations of kinetic optical occlusion, figural change consistent with a rigid object and an occluding edge leads to perceived occlusion of an unchanging figure, but other figural changes might appear as deformation. Kinetic subjective contours may be perceived only when the temporal relations of figural interruptions could result from a rigid object in motion. Alternatively, it is possible that occlusion patterns given by a deforming central figure could lead to a perception of a unified, nonrigid entity. Other possible constraints on the appearance of kinetic subjective contours, for example, whether occlusion relations over time must be consistent with an entity moving at a constant speed, also remain to be investigated.

The differences between kinetic and static subjective contours may reflect only the different requirements for specifying occlusion in dynamic and static arrays. While the former rely on kinetic optical occlusion, only interruption of reasonably regular or symmetrical figures may indicate occlusion in the static case. In both cases, several appropriately related instances of occlusion give rise to subjective fig- ures. This unified view of kinetic and static subjective contours as dependent on occlusion, however specified, is an extension of Coren's (1972) account of static subjective contours.

Perception of unitary and definitely shaped figures from spatial and temporal relationships in kinetic subjective contours may also be related to the work of Johansson and others with moving dot patterns (Johansson, 1975; Johansson, von Hofsten, \& Jansson, 1980). While motion relationships in moving dot patterns can specify unity and form, they do not in general yield the clear edges, perceived opacity of the specified figure, and occlusion of background patterns present in kinetic subjective contours. However, these phenomenal differences may be more the result of differences in the richness of the stimuli than in the perceptual mechanisms involved.

It is less clear what kinetic subjective contours have in common with other research on temporal integration in visual form perception. Parks (1965) demonstrated that adults easily recognize patterns that are shown moving back and forth behind a narrow slit. Hochberg (1968) described other phenomena of this sort and hypothesized that ordinary visual perception often involves the integration of successive glances into "schematic maps." Although integration of views in aperture viewing readily leads to form identification, these phenomena seem to differ from kinetic subjective contours in that the perceived form never seems to be wholly in view. Although the necessary information in kinetic subjective contours displays is displayed over time, it produces perceptual experiences in which the whole figure is plainly visible at one time. Theoretically, the aperture viewing phenomena are ordinarily interpreted as explicitly representational: they are consistent with storage of information from individual glimpses and its integration into mental structures (Hochberg, 1968). The kinetic subjective contour phenomenon may not involve intermediate levels of representation, but may be based instead on perceptual mechanisms that are directly sensitive to motion relationships. ${ }^{\star}$

Finally, kinetic subjective contours are quite different from a superficially similar phenomenon-the "moving visual phantoms" reported by Tynan and Sekuler (1975). A moving sinusoidal or square-wave luminance grating surrounding a dark, stationary area leads to perception of faint, white "phantom" stripes across the empty area. This phenomenon differs from kinetic subjective contours in both its appearance and its inducing conditions. In appearance, the phantom stripes are much dimmer than the moving white areas above and below them (Tynan \& Sekuler, 1975). They look translucent and have vague edges. Kinetic subjective figures appear opaque with crisp boundaries. Moreover, kinetic subjective contours consist only of perceived boundaries, not ap- 
parent brightness differences, in physically homogeneous regions. (For further discussion of boundaries in physically and perceptually homogeneous space, see Kellman \& Cohen, 1983). Moving phantoms and kinetic subjective contours occur under quite different conditions. Phantoms require a dark viewing environment, and they are more distinct with lowcontrast gratings (Tynan \& Sekuler, 1975). Kinetic subjective contours, on the other hand, are quite robust in ordinary illumination, with high contrast between the inducing elements and the background. Perhaps the most important differences are that kinetic subjective contours depend on kinetic optical occlusion, and their inducing events need not occur simultaneously. Phantoms do not involve kinetic optical occlusion, and they require simultaneous moving regions above and below the empty area. An interesting variation of the phantom effect is that surrounding an empty black area with moving white dots against a black background can induce faint white dots in the empty area (Tynan \& Sekuler, 1975). The phantom effects seem to require repetitive luminance patterns and to have little to do with perception of unity and boundaries in occlusion situations. In sum, the existence of kinetic subjective contours is to some extent predictable (and was predicted) from existing knowledge about occlusion, static subjective contours, and the importance of temporal relationships in visual perception. Moving phantoms are as yet unexplained and seem unlikely to be related to kinetic subjective contours.

The existence of kinetic subjective contours suggests that the visual system is highly sensitive to relationships among occluding edges separated in time and space. The minimum conditions for contour perception require neither the presence of luminance differences all along an edge nor the simultaneous specification of the edge at two or more locations.

Unpracticed observers' perception of figural unity and accurate shape under these conditions suggests that such relationships are utilized in normal perception. While many boundaries among objects result in spatially and temporally continuous luminance differences in reflected light, perhaps ordinary contour and form perception do not always utilize such differences along the entire boundaries. Observations with kinetic and static subjective contours suggest that specifying points of change in contour direction-contour inflection points-is crucial for clear subjective figures to be perceived, whereas luminance differences along straight or smoothly curving edges are not necessary. Ordinary contour and object perception may rely most heavily on the inflection points of an object's edges. Perhaps especially under conditions of object or observer movement, spatial and temporal relations among inflection points may be adequate to specify object unity and form.

\section{REFERENCES}

Brigner, W. L., \& Gallagher, M. B. (1974). Subjective contour: Apparent depth or simultaneous brightness contrast? Perceptual \& Motor Skills, 38, 1047-1053.

Coren, S. (1972). Subjective contours and apparent depth. Psychological Review, 79, 359-367.

Dumais, S. T., \& Bradley, D. R. (1976). The effects of illumination level and retinal size on the apparent strength of subjective contours. Perception \& Psychophysics, 19, 339-345.

Frisby, J. P., \& Clatworthy, J. L. (1975). Illusory contours: Curious cases of simultaneous brightness contrast? Perception, 4, 349-357.

Gibson, J. J. (1979). The ecological approach to visual perception. Boston: Houghton Mifflin.

Gibson, J. J., Kaplan, G. A., Reynolds, H. N., \& Wheeler, $K$. (1969). The change from visible to invisible: A study of optical transitions. Perception \& Psychophysics, 5, 113-116.

Hochвe Ro, J. (1968). In the mind's eye. In R. N. Haber (Ed.), Contemporary theory and research in visual perception. New York: Holt, Rinehart \& Winston.

HochBera, J. (1982). How big is a stimulus? In J. Beck (Ed.), Organization and representation in perception. Hillsdale, NJ: Erlbaum.

Johansson, G. (1975). Visual motion perception. Scientific American, 232(6), 76-88.

Johanssun, G., von Horsten, C., \& Jansson, G. (1980). Event perception. Annual Review of Psychology, 31, $27-63$.

KanizsA, G. (1955). Margini quasi-percettivi in campi con stimolazione omogenea. Rivista di Psicologia, 49, 3-19.

Kanizsa, G. (1979). Organization in vision: Essays on Gestalt perception. New York: Praeger.

Kaplan, G. A. (1969). Kinetic disruption of optical texture: The perception of depth at an edge. Perception \& Psychophysics, 6, 193-198.

Kellman, P. J., \& Cohen, M. H. (1983). Subjective contours in physically and perceptually homogeneous space. Manuscript submitted for publication.

Michotte, A., Thinés, G., \& Crabbé, G. (1964). Les complements amodaux dex structures perceptives (Studia psychologica). Louvain: Publications Universitaires de Louvain.

PArks, T. (1965). Post-retinal visual storage. American Journal of Psychology, 78, 145-147.

Rock, I., \& Anson, R. (1979). Illusory contours as the solution to a problem. Perception, 8, 665-681.

SchumanN, F. (1904). Beitrage zur Analyse der Gesichtswahrnehmungen: 1. Einige Beobachtungen über die Zusammenfassung von Gesichtseindrucken au Einheiten. Zeitschrift für Psychologie, 23, 1-32.

SiEGEL, S. (1956). Nonparametric statistics for the behavioral sciences. New York: McGraw-Hill.

Tynan, P., \& Sexuler, R. (1975). Moving visual phantoms: A new contour completion effect. Science, 188, 951-952.

Ullman, S. (1979). The interpretation of visual motion. Cambridge, MA: M.I.T. Press.

\section{NOTES}

1. A version of the binomial test is used instead of the McNemar test when the expected frequency of changes in response between two displays is less than 5 (Siegel, 1956, pp. 66-67).

2. The authors thank one of the anonymous reviewers for raising this possibility.

3. One subject reported a quite different impression from these displays, one which the experimenters had also noticed previously. The white inducing elements were seen as a white surface appearing through holes in an overlying black surface. The subjective figure was seen as behind this black surface, but in front of the white surface. Thus, it interrupted the white areas where it extended into 
the holes. The subjective figure seen this way is quite well defined, even though much of its perimeter is behind the nearer black surface. It is an excellent example of amodal completion (Michotte et al., 1964), although subjective contours are ordinarily completed modally (Kanisza, 1979). It is our observation that once one is aware of the two possible locations of the subjective figure, these displays exhibit frequent reversals from one percept to the other. The locating of the subjective figure behind a nearer surface with holes is logically possible as well for ordinary static subjective contcur displays, but it does not seem to occur. Thus, this bistability may be unique to kinetic subjective contours.

4. In general, studies of "integration of successive glimpses" and "direct pickup of information over time" have involved separate phenomena and theoretical treatment. Whether phenomena described differently in these terms always rely on different mechanisms is not as clear. Both theoretical clarification and further empirical work may be needed to decide which, if any, perceptual abilities are subserved by detectors of temporally extended information, and which are derived from computations on representations of momentary input (for a useful discussion, see Hochberg, 1982).

(Manuscript received July 18, 1983;

revision accepted for publication December 16, 1983.) 